\title{
A MORTE DE DEUS: A GRAMÁTICA EM QUESTÃO
}

\section{Robione Landim ${ }^{1}$}

\begin{abstract}
RESUMO
No fragmento 346 do livro $A$ gaia ciência, Nietzsche recusa a caracterização de si mesmo enquanto ateu. Por que Nietzsche recusa a classificação de ateísta? Estaria no sangue ser teísta, religioso? O caminho que esse trabalho seguirá para discutir essa temática passa pela compreensão da morte de Deus enquanto crítica a todo tipo de fundamento último. Ademais, ainda se destacará a relação presente entre a noção de Deus-fundamento e a linguagem. Desse modo, o presente artigo orbitará em torno do seguinte problema: em que medida a morte de Deus coloca em questão a crença na gramática?
\end{abstract}

Palavras-chave: Nietzsche. Morte de Deus. Ateísmo. Linguagem.

\begin{abstract}
In fragment 346 of the book The Gay Science, Nietzsche refuses to characterize himself as an atheist. Why does Nietzsche refuse to be classified as an atheist? Was it in the blood to be theistic, religious? The path that this work will follow to discuss this theme is to understand the death of God as a criticism of all kinds of ultimate foundations. Furthermore, the present relationship between the notion of God-foundation and language will also be highlighted. Thus, this article will orbit around the following problem: to what extent does God's death call into question the belief in grammar?
\end{abstract}

Keywords: Nietzsche. Death of God. Atheism. Language.

"Quem somos nós, afinal? Quiséssemos simplesmente nos designar, com uma expressão mais velha, por ateu ou ímpio, ou ainda imoralista, não acreditaríamos nem de longe estar caracterizados com isso [...]" (NIETZSCHE, 2001, §346, p. 238-239). Com esta citação queremos destacar que Nietzsche não compreende a expressão da morte de Deus como um discurso meramente ateu. Ele recusa ser caracterizado enquanto ateu. Por que Nietzsche recusa a classificação de ateísta? O faz, mas não para afirmar-se enquanto teísta, religioso. A rejeição por ser considerado ateu é assumida para

\footnotetext{
${ }^{1}$ Graduado em Filosofia (UniAcademia) e Doutor em Ciência da Religião (UFJF). Professor do curso de Filosofia do Centro Universitário UniAcademia.

E-mail: ralandim@yahoo.com.br.
} 
mostrar o quanto essa fórmula ainda não é o suficiente para expressar uma crítica apropriada à religião, tampouco para impedir que a crença em um novo ideal de fé continue sempre viva. "Donde os limites da expressão 'ateísmo', quando aplicada à Ilustração, e o quanto é duvidoso considerar o século XVIII como fundamentalmente irreligioso" (MOURA, 2005, p. 9). Em Nietzsche, a proposição "Deus está morto" é mais radical do que a expressão de uma tese ateísta. Esta qualificação está longe de caracterizar o filósofo Nietzsche ${ }^{2}$. Portanto, o caminho que esse trabalho seguirá para discutir essa temática passa pela relação que Nietzsche estabelece entre a noção de Deus-fundamento e a linguagem. Desse modo, o presente artigo visa apresentar essa articulação. Ou seja, a morte de Deus é uma questão de gramática. A crença nesta viabiliza o surgimento de Deus.

Nascido numa família cristã, Nietzsche cresceu cercado por pastores protestantes - seu pai era pastor -, respirando um ar de religiosidade devota (PENZO; GIBELLINI, 1998). Nas palavras de uma estudiosa, "O Cristianismo foi o fundamento material e emocional familiar que preencheu sua infância com amor e segurança, um calor humano que ele nunca deixou de valorizar" (YOUNG, 2014, p. 6). Entretanto, na sua fase madura Nietzsche se mostra hostil ao cristianismo e sua moral de escravos. Essa crítica se radicaliza com o anúncio da morte de Deus.

Muito embora no fragmento 343 d'Agaia ciência (2001) Nietzsche associe o fato de que Deus está morto à descrença no Deus cristão, aquela mensagem não se destina exclusivamente ao Deus cristão ${ }^{3}$, mas a todo tipo de fundamento absoluto, em cuja crença mostra a pretensa sacralidade de sua origem. Na história do pensamento ocidental Deus é considerado como um fundamento último, na medida em que simboliza um lugar (que no fun-

\footnotetext{
${ }^{2}$ Carlos Alberto Ribeiro de Moura (2005) embora afirme que a morte de Deus "retoma o tema do 'ateísmo' de Nietzsche" (MOURA, 2005, p. 1), ele observa que este ateísmo merece aspas. $\mathrm{O}$ recurso deste sinal indica a radicalidade, amplitude e especificidade do "ateís mo" nietzschiano em relação àquele que era aplicado à Ilustração e à filosofia do século XIX alemão. Em alguma medida, destacamos que o emprego das aspas no "ateísmo" de Nietzsche sinaliza que essa expressão é deficiente para examinar a passagem da morte de Deus em Nietzsche.

${ }^{3}$ Não obstante a "morte de Deus" carregue o sentido tradicional de fim da validade da ideia de um ser transcendente, ela ainda significará "a recusa de todos os substitutos, mais ou menos disfarçados, do infinito teológico, todas as versões do 'Ser genérico'; enfim, a morte de Deus será indissociável da desvalorização de todos os valores por ele sancionados" (MOURA, 2005, p. 20). Noutras palavras, o fundamento que servia de sustentação àqueles valores foi abalado, perdeu sua força enquanto suporte. Deus está morto!
} 
do é um não-lugar por se furtar à historicidade) capaz de descrever de modo adequado a estrutura da realidade. Ao fundar uma ordem estável e necessária, Deus, enquanto fundamento, alimenta a crença de que é possível alcançar algo que esteja "por detrás", uma estrutura do ser que funciona como paradigma (PIRES, 2016). Mas como essa noção de Deus aparece?

Nietzsche reconhece em seus escritos que essa concepção de Deusfundamento ganha importância na medida em que torna a vida humana possível. Mas como isso se dá? A via pela qual será abordada essa temática passa pela relação que Nietzsche estabelece entre a noção de Deus-fundamento e a linguagem. Para início de conversa, o autor afirma, em Crepúsculo dos ídolos: "Receio que não nos livremos de Deus, pois ainda cremos na gramática" (NIETZSCHE, 2006, §5, p. 28). A citação nietzschiana afirma um vínculo entre Deus e a linguagem. Sendo assim, como entender a relação entre Deus e a gramática?

\section{A crença em Deus como resultado da fé na gramática}

No ensaio Sobre verdade e mentira no sentido extra-moral, escrito em 1873, Nietzsche nos oferece pistas para pensar a questão. Nesse texto em particular, ele passa a pensar a linguagem enquanto relação. Faz ver que nela se aloja a crença de que se podem apreender as coisas tal como são. No início desse escrito, o filósofo ironiza a postura de arrogância e pretensão de certos "animais inteligentes" que inventaram o conhecimento. Este "Foi o minuto mais soberbo e mais mentiroso da 'história universal': mas também foi somente um minuto" (NIETZSCHE, 1978, §1, p. 45). O alvo de Nietzsche é a invenção da inteligência que foi concebida como uma vantagem humana ante os demais seres "inferiores". Em sua abordagem crítica, o intelecto humano não é visto como um órgão poderoso, nem voltado especificamente para o conhecimento. Para o filósofo alemão, o intelecto "foi concedido apenas como meio auxiliar aos mais infelizes, delicados e perecíveis dos seres, para firmá-los um minuto na existência” (NIETZSCHE, 1978, §1, p. 45). O intelecto, enquanto instrumento fantástico de sobrevivência de uma espécie frágil, não tem como compromisso primeiro a verdade, nem se coloca com o pretexto de compreender melhor o mundo. O conhecimento 
aqui é apresentado como um mecanismo humano, cujo efeito mais geral consiste no disfarce e não nos conduz em parte alguma à verdade. Dito de outro modo, o conhecimento trabalha como instrumento de poder, isto é, o nosso aparato de conhecimento não é disposto para o "conhecimento em si", mas é desenvolvido sob as condições de existência, na medida em que favorece a conservação e a expansão da vida. Conhecer, portanto, não significa explicar. Ele não tem por objetivo atingir uma verdade, mas assenhorar-se da realidade (esquematizar, impor ao caos regularidade e formas) a fim de tomá-la a seu serviço, suficiente à nossa necessidade prática.

Discorrendo sobre o que poderia ser o "estado de natureza", Nietzsche começa a imaginar a existência dos homens antes da vida em comunidade; eles se achariam num mundo onde reinava a máxima "bellum omnium contra omnes" ("guerra de todos contra todos"). Como os animais, só se conheciam comparando-se uns aos outros; apreendiam tudo a respeito de si mesmos na relação entre sua força de ataque e defesa e a dos outros.

No entanto, a fim de superar aquela máxima da luta de todos contra todos e estabelecer uma vida em coletividade, os indivíduos mais fracos, os mais desafortunados, temendo não conseguir subsistir, perceberam ser necessário encontrar um meio para conservarem-se. O que eles fizeram? Para preservar e garantir sua existência, o indivíduo mais fraco lançou mão de um tratado de paz. Vale destacar que esse tratado, como aponta Pires (2016), não corresponde a uma decisão meramente política (PIRES, 2016, p. 10). Ele traz consigo implicações outras, como, por exemplo, o forjar da noção de verdade. Sobre isso, afirma Nietzsche em Sobre verdade e mentira no sentido extra-moral,

Agora, com efeito, é fixado aquilo que doravante deve ser 'verdade', isto é, é descoberta uma designação uniformemente válida e obrigatória das coisas e a legislação da linguagem dá também as primeiras leis da verdade: pois surge aqui pela primeira vez o contraste entre verdade e mentira (NIETZSCHE, 1978, §1, p. 46).

A partir desse momento é estabelecido um acordo com relação ao sentido das palavras. Fixar o sentido destas viabiliza a comunicação e a vida em sociedade. Fica estabelecido um "tratado de paz" que nada mais é do que o acordo em torno de um parâmetro que unifique as diversas linguagens. Dito de outra maneira, para manter a vida em coletividade, impôs-se a todos 
os membros do grupo a obrigação de empregar as designações usuais, convencionalmente estabelecidas.

Desse modo, o mentiroso é aquele que não se submete ao que foi convencionado pelo grupo. Ele usa as designações válidas, as palavras, para fazer aparecer o não-efetivo como efetivo. Para usar um exemplo empregado por Nietzsche (1978): digo que "sou rico", quando, na verdade, para meu estado seria precisamente "pobre" a designação correta. Ao passo que ser verídico, consiste em conformar-se com a maioria, ao que foi acordado.

O problema, entretanto, é que com o passar do tempo pode o ser humano se esquecer de que aqui fora estabelecido um acordo. Os homens criam a linguagem, mas se esquecem dessa autoria e a transforma na "arte do disfarce" e do engano.

No homem essa arte do disfarce chega a seu ápice; aqui o engano, o lisonjear, mentir e ludibriar, o falar-por-trás-das-coisas, o representar, o viver em glória de empréstimo, o mascarar-se, a convenção dissimulante [...], é a tal ponto a regra e a lei que quase nada é mais inconcebível do que como pôde aparecer entre os homens um honesto e puro impulso à verdade. Eles estão profundamente imersos em ilusões e imagens de sonho, seu olho apenas resvala às tontas pela superfície das coisas e vê "formas", sua sensação não conduz em parte alguma à verdade, mas contenta-se em receber estímulos e como que dedilhar um teclado às costas das coisas [...] (NIETZSCHE, 1978, §1, p. 46).

Em Verdade e mentira... a linguagem não exprime de forma adequada a realidade. Tanto que Nietzsche comenta "As diferentes línguas, colocadas lado a lado, mostram que nas palavras nunca importa a verdade, nunca uma expressão adequada: pois senão não haveria tantas línguas" (NIETZSCHE, 1978, §1). No entanto, o criador da linguagem esquece que ela nunca expressa algo completamente, mas apenas destaca uma marca da coisa; com esse esquecimento passa a acreditar inconscientemente que a linguagem é um espelho que reflete as coisas como elas realmente são "em si”, que imagina um instinto de verdade. Ou seja, acredita-se que o conhecimento é capaz de acessar uma realidade estável subjacente à mudança.

Consequentemente, já não se entende que a linguagem expressa o modo como nós nos relacionamos com as coisas. Assim, a verdade também não é mais apenas um mecanismo para a conservação da vida, mas passa a se configurar como espelho do real, ou seja, como adequação do intelecto à 
realidade. Nesse momento em que se estabelece uma designação uniformemente válida e obrigatória para as coisas, o mentiroso é compreendido como aquele que recusa a "realidade" petrificada nas palavras, rejeita a univocidade que lhe foi imposta. Rebelando-se contra o já estabelecido na estável ordem social, ele introduz o risco. Como Pilatos ${ }^{4}$, Nietzsche pergunta "O que é a verdade?". Eis a resposta:

Um batalhão móvel de metáforas, metonímias, antropomorfismos, enfim, uma soma de relações humanas, que foram enfatizadas poética e retoricamente, transpostas, enfeitadas, e que, após longo uso, parecem a um povo sólidas, canônicas e obrigatórias: as verdades são ilusões, das quais se esqueceu que o são, metáforas que se tornaram gastas e sem força sensível, moedas que perderam sua efígie e agora só entram em consideração como metal, não mais como moedas (NIETZSCHE, 1978, §1, p. 48).

$\mathrm{Na}$ perspectiva nietzschiana, não existe instinto de conhecimento no sentido de uma inclinação natural para a verdade, de um amor à verdade. A verdade é, antes de tudo, um valor. Ou seja, ela não é tematizada propriamente no rol da epistemologia que teria por intenção estabelecer critérios de demarcação entre o conhecimento verdadeiro e o falso. A noção de verdade aqui, para além da teoria do conhecimento, se articula com o âmbito político-social-moral (MACHADO, 1999). Em outras palavras, o que se chama verdade é uma obrigação que a sociedade impõe como condição de sua própria existência: uma obrigação moral de mentir segundo uma convenção estabelecida.

Indissociável da linguagem, ela auxilia para a manutenção da vida gregária, da coexistência pacífica entre os homens. Isso significa dizer que o homem não ama necessariamente a verdade: deseja suas consequências favoráveis. O homem também não odeia a mentira. Não suporta os prejuízos por ela provocados. Instituída por convenção, não diz respeito às próprias coisas, mas à relação que os homens estabelecem com elas. Mas como a linguagem se articula com a noção de Deus-fundamento?

Nietzsche compreende as categorias filosóficas como meros hábitos gramaticais. Foi a crença na gramática que consolidou a crença na relação de causa e efeito. Daí também sua crítica ao cogito cartesiano, que segundo Nietzsche é resultado de um velho hábito gramatical de atribuir um ator a

\footnotetext{
${ }^{4}$ JO, 18, 38.
} 
toda ação. É a partir desse hábito que se chega à ideia de sujeito, de vontade, de eu, de Deus. Na medida em que Nietzsche toma a linguagem como retórica, para ele não há uma adequação da realidade, pois o mundo é um constante devir. Enquanto retórica, a linguagem não está dirigida para a verdade, para a essência das coisas (MOURA, 2005). Porém, o impulso à verdade apareceu desse esquecimento.

Se assim entendemos o nascimento da linguagem, entendemos nesse mesmo ato o nascimento da noção de Deus-fundamento, pois foi justamente a crença de que na realidade subjaz certa estabilidade em meio à mudança que viabilizou a vida em sociedade. Ademais, foi também essa crença que tornou possível o desenvolvimento científico, o controle dos instintos para que se pudesse organizar uma civilização (PIRES, 2016).

Ainda que por outros caminhos, Heidegger trilha por sendas muito próximas a Nietzsche. A respeito da noção de Deus na filosofia, vejamos como ele tematiza:

O Deus entra na filosofia pela de-cisão, que nós primeiro pensamos como o átrio em que se manifesta a diferença entre ser e ente. A diferença constitui o traçado básico no edifício da essência da metafísica. A de-cisão dá como resultado e oferece o ser enquanto fundamento a-dutor e pro-dutor, fundamento que necessita, ele próprio, a partir do que ele fundamenta, a fundamentação que lhe é adequada, quer dizer, a causação pela coisa (causa) mais originária (Ur-sache). Esta é a causa como causa sui. Assim soa o nome adequado para o Deus na filosofia (HEIDEGGER, 1971, p. 99).

Dito de outra forma, Deus é uma palavra que concentra em si uma gama de conceitos metafísicos tradicionais. Na busca pela causa do ser, a concepção de Deus é vislumbrada como causa primeira, fundamento do ser, justamente para não se regredir ad infinitum. Nessa perspectiva, Deus é aquele que assegura ao devir uma estrutura que fornece sentido a uma pluralidade de elementos caóticos. O problema não está em conceber um sentido, mas em pensar que esse sentido se constitui como um em si.

Com efeito, a raiz metafísica do conhecer como necessidade de segurança leva o homem a conceber Deus como último horizonte de segurança e de verdade absoluta, e a dimensão metafísica da fé como busca de uma segurança última (PENZO; GIBELLINI, 1998). Quer dizer que além de representar o princípio estruturador do devir no plano teorético, Deus aparece 
também como sentido existencial para as ações humanas. O conceito de Deus, portanto, justificaria o devir teórica e praticamente.

Posto isso, queremos destacar que essa caracterização de Deus não o vê como apenas uma entidade religiosa que se mantém exclusivamente no âmbito de realização de nossas crenças. Segundo Heidegger, "a este Deus não pode o homem nem rezar, nem sacrificar. Diante da causa sui, não pode o homem nem cair de joelhos por temor, nem pode, diante deste deus, tocar música e dançar" (HEIDEGGER, 1971, p. 99). No interior do pensamento metafísico-cristão, a noção de Deus é compreendida como um fundamento ontológico, assegurando o ente enquanto um ente criado. Ele entra na filosofia, portanto, como uma exigência lógica do pensamento que almeja um fundamento absoluto para saciar um longo desejo que é necessário ao homem para viver com uma consciência de segurança.

Mas Deus morreu. Quer dizer que aquelas estruturas de pensamento e de linguagem entraram em colapso. Chegaram ao fim certa visão do universo e uma maneira de organizar a vida. Por isso, o acontecimento da morte de Deus é vivenciado e experimentado pelo homem ocidental como uma sensação de desespero, visto que ele marca o fim de uma estrutura sólida de caráter metafísico-existencial (CABRAL, 2014) dessa exigência de segurança para viver a vida. No aforismo 125, a gravidade da morte de Deus que provocou essa atmosfera sombria é ilustrada através das perguntas levantadas pelo homem desvairado:

Que fizemos nós, ao desatar a terra do seu sol? Para onde se move ela agora? Para onde nos movemos nós? Para longe de todos os sóis? Não caímos continuamente? Para trás, para os lados, para a frente, em todas as direções? Existem ainda 'em cima' e 'embaixo'? Não vagamos como que através de um nada infinito? Não sentimos na pele o sopro do vácuo? Não se tornou ele mais frio? Não anoitece eternamente? Não temos que acender lanternas de manhã? (NIETZSCHE, 2001, §125, p. 147-148).

No limite, a morte de Deus em Nietzsche coloca em questão esse sentido de divino enquanto uma ideia reguladora de fundamentação absoluta. É essa a compreensão de divino que quer descrever os funerais. Dito de outro modo, o anúncio da morte de Deus em Nietzsche intenciona indicar que quem morreu foi o Deus da onto-teologia, isto é, "o deus da metafísica e, também, o da teologia, na medida em que a teologia repousa sobre a me- 
tafísica da causa primeira, do ser necessário, do primeiro motor, concebido como a origem dos valores e como o bem absoluto" (RICOEUR, 1978, p. 372). O Deus que morre é Aquele apreendido graças aos conceitos, que, segundo Nietzsche, seriam apenas teias que envolvem a face de Deus. Nesse sentido, a crítica nietzschiana arrasta consigo a noção de Deus cristão também. Pois, o conceito cristão de Deus, segundo Nietzsche, é um dos mais corruptos já alcançados na terra, já que "transfigurou-se em algo sempre mais fino e mais pálido, tornou-se 'ideal', 'puro espírito', tornou-se 'absolutum' [algo absoluto], 'coisa-em-si'”' (NIETZSCHE, 2007, §17, p. 23).

O Deus cristão foi elevado a uma instância suprema externa e superior à existência, descolado da realidade, tornado autônomo, supremo, fonte de sentido universal e padrão normativo, metafísico. Esse Deus como coisaem-s1, metafisicamente compreendido, torna-se moral e, com isso, enquanto instância suprema, toda a realidade passa a ser julgada a partir de tal instância. Consequentemente, a vida atual, vista daquele ponto, é medida como inferior, pois encontra-se subordinada a uma verdade, a um mundo verdadeiro que serve de normatização para essa existência, considerada doravante como uma espécie de carência ontológica e por isso deve ser corrigida. Deus foi tornado um ideal, um puro absoluto.

\section{A morte de Deus para além do ateísmo}

Em $O$ Anticristo, Nietzsche define o Deus da metafísica como "Deus-aranha" (NIETZSCHE, 2007, §18, p. 23). Aos olhos de Nietzsche, o Deus-cristão-metafísico se volta contra as condições fundamentais da vida. Entendido como um ideal, esse divino aponta para outro "mundo verdadeiro" uma existência idealizada, cuja felicidade plena jamais será alcançada nessa vida atual. Sua sustentação é uma espécie de edifício apoiado em nuvens, ou seja, extremamente frágil por não ter nenhum fundamento último sólido para se apoiar - um nada divinizado, ele procura negar o caráter agonístico e "ameaçador" da vida e, ainda por cima, cria estratégias não apenas de negação, mas de combate à vida, aos seus antagonismos.

A morte de Deus, então, assinala que "não há um fundamento definitivo, e nada mais" (VATTIMO, 2004, p. 9). Quer dizer que para compreen- 
der a amplitude desse anúncio não se pode interpretá-lo como declaração de ateísmo no sentido tradicional do termo. Ao anunciar que Deus está morto, Nietzsche afirma a impossibilidade de se alcançar qualquer fundamento último e definitivo, quebrando a marteladas a ideia de que o ser possui uma estrutura acessível à razão e, com efeito, da possibilidade de fundamentações últimas. Em resumo, a morte de Deus é entendida enquanto a experiência da decadência de tudo que se quis ou queira se portar como fundamento último, isto é, de qualquer estrutura absoluta da realidade.

Neste sentido, argumenta Vattimo (2004), a morte de Deus (bem como o fim da metafísica) é um acontecimento que consiste em promover uma mudança na vida daqueles que recebem o seu anúncio. Que tipo de mudança é essa?

Com a morte de Deus, isto é, com o fim da visão do ser como uma estrutura objetiva, sobra-nos a contingência e historicidade do nosso existir. Em termos filosóficos e hermenêuticos, Vattimo (2004) sustenta que a partir de agora o ser só pode ser pensado como um evento, assim como a verdade não mais pode ser o reflexo de uma estrutura eterna do real e sim como uma mensagem histórica que devemos ouvir e à qual somos chamados a dar uma resposta. Com outras palavras, mediante o anúncio da morte de Deus, Nietzsche contribui de maneira decisiva para o surgimento e o desenvolvimento daquilo que Vattimo (2010) denominou de "ontologia hermenêutica contemporânea" (VATTIMO, 2010, p. 134), isto é, a tendência filosófica que assume como tema central o fenômeno da interpretação. Esta torna o traço essencial da existência humana a base para realizar a crítica da metafísica tradicional.

Uma vez entendendo a morte de Deus como o fim de um fundamento último e não enquanto uma metafísica ateísta, Vattimo (2004) mostra como as metanarrativas que pautavam a mera exclusão da religião também perdem seu poder de legitimação. Reconhecendo-se que não há fundamentos últimos, também não há mais razões suficientemente legítimas para ser ateu. Logo, uma das principais consequências, segundo Vattimo (2004), da morte de Deus foi justamente tornar possível um terreno propício para uma possibilidade renovada da experiência religiosa. Pois, segundo o pensador italiano, somente uma filosofia "absoluta" pode se sentir autorizada a negar 
a experiência religiosa. O Deus que se pode crer no contexto pós-moderno não é mais aquele Deus das certezas metafísicas, mas tão-somente, o Deus do livro.

Trata-se de um Deus que se apresenta a nós somente no livro, que não "existe" como uma realidade objetiva fora do anúncio de salvação que, de formas historicamente mutáveis e predispostas a uma contínua reinterpretação por parte da comunidade dos crentes, nos foi feito pela Sagrada Escritura e pela tradição viva da Igreja (VATTIMO, 2004, p. 15) .

A questão para Nietzsche no que diz respeito à noção de Deus não gira simplesmente em torno dos argumentos lógicos favoráveis ou contrários a essa hipótese. Embora essa temática, principalmente na vertente do empirismo, tenha se tornado e ainda hoje seja objeto de debate, nesse caso, ao que parece, Nietzsche não está muito interessado. Antes, Nietzsche busca compreender a noção de Deus não em termos meramente psicológicos, mas no seu impacto na crítica da civilização (RICOEUR, 1978). Em outros termos, ele (e outros autores do século XIX, tais como Freud) percebe que a noção de Deus não é apenas um problema abstruso, objeto de consideração de filósofos e teólogos. Ele a vê como uma crítica da cultura, uma vez que da ideia de Deus reverberam noções morais, visões de mundo, interpretações sobre a vida e a história. Em suma, o conceito de Deus se mostra como fundamento de uma visão de civilização e cultura.

Nesse sentido, quando Nietzsche desfere suas críticas a Deus, ele tem clareza de que não se trata apenas de um conceito lógico restrito. Antes, ele abala o fundamento mesmo de toda uma tradição que se construiu com base nessa noção, mesmo que nem sempre ela tenha atendido pelo nome de Deus (no sentido de que outras noções assumem características de Deus, ainda que seja sujeito, consciência, etc). Quer dizer que,

Enquanto as sandálias de Deus forem calçadas pela Razão, arte, cultura, Geist, imaginação, nação, humanidade, Estado, povo, sociedade, moral ou algum outro enganoso substituto, o Ser Supremo não está exatamente morto. Pode estar mortalmente doente, mas delegou suas questões a este ou àquele emissário, tendo cada um

\footnotetext{
${ }^{5} \mathrm{O}$ modo de crer no horizonte pós-moderno é marcado por uma aposta arriscada. Fé aqui não tem a ver com a aceitação de dogmas rigidamente definidos ou de disciplinas impostas por uma autoridade. A igreja é vista como comunidade de crentes que, na caridade, ouvem e interpretam livremente o sentido da mensagem cristã.
} 
deles como parte de sua missão convencer homens e mulheres de que não há motivo de alarme, de que os negócios continuarão sendo conduzidos como sempre, apesar da ausência do proprietário, e de que o diretor em função é perfeitamente capaz de atender a todas as necessidades (EAGLETON, 2016, p. 141).

Segundo Nietzsche (2006), Deus é o termo que concentra em si uma diversidade de conceitos metafísicos tradicionais: "todos os valores mais altos são de primeira ordem, todos os conceitos mais elevados, o ser, o incondicionado, o bem, o verdadeiro, o perfeito" são tomados pelo "estupendo conceito de 'Deus"' (NIETZSCHE, 2006, §4, p. 27). Vale dizer que ele mesmo era o signo conceitual para se pensar o absoluto como aquela instância “em si” estruturadora e normatizadora de ações e pensamentos.

Mais ainda. Segundo Rubem Alves (1988), Nietzsche, com sua visão de profeta, compreendeu que a história da civilização ocidental estava marcada por uma estrutura de repressão legitimada pela religião. Em suas palavras, afirma o teólogo:

Em nome de Deus nega-se um corpo; o ideal cristão é o ascetismo. Em nome de Deus nega-se a vontade, a espontaneidade; o ideal cristão é a obediência, o camelo que aceita todas as cargas sem reclamar. Em nome de Deus nega-se o tempo, porque o seu mundo é o mundo da eternidade. Em nome de Deus nega-se a liberdade ao homem para criar um futuro novo, porque todos os valores já haviam sido codificados no passado (ALVES, 1988, p. 78).

Assim, o nome Deus deixa entrever uma estrutura de repressão. Consequentemente, a sua morte marca o fim dessa atmosfera violenta. Por essa razão, de acordo com Rubem Alves (1988), a proclamação da morte de Deus para Nietzsche soa como uma "boa nova", pois ela significa permissão para a vida, para o mundo. Diante dessa notícia, afirma Nietzsche, "nos sentimos como iluminados por uma nova aurora; nosso coração transborda de gratidão, espanto, pressentimento, expectativa - enfim o horizonte nos aparece novamente livre" (NIETZSCHE, 2001, §343, p. 234).

Desse modo, associar o nome de Nietzsche ao ateísmo no sentido estrito da palavra é uma consideração inapropriada, revelando-se ainda uma leitura apressada de sua obra. Ademais, essa qualificação não cabe ao tema da morte de Deus em Nietzsche, porque o sentido tradicional do termo "ateísmo" faz com que o a-teu esteja ainda em relação a Deus, embora pretenda negá-lo. Negar esse Deus pode ser apenas mais um modo de mantê-Lo vivo. 
Noutras palavras, "Deus encontra em verdade um refúgio em meio à descrença dos homens porque a descrença não pode de maneira alguma prescindir dele em sua estruturação" (CASANOVA, 2003, p. 340).

Assim, a rejeição nietzschiana de ser qualificado como ateu possibilita esclarecer o que está sendo entendido por tal ideia. Em resumo, ele nega a alcunha de ateísmo no sentido estrito do termo. Sua filosofia não se restringe apenas em negar a Deus, como se esse devesse ser erradicado do nosso meio. Segundo Vattimo (2004), defender tal proposição continuaria a valer para ele como uma pretensa verdade absoluta ou, se quiser, um princípio metafísico (como estruturação lógica necessária na qual a realidade se espelha), só que ao revés. Assim, o anúncio da morte de Deus não está propondo uma metafísica ateísta, senão incorreria na pretensão de descrever adequadamente a realidade como algo do qual Deus foi excluído. Reconhecendo-se que não há fundamentos últimos, também não há mais razões suficientemente legítimas para ser ateu.

Desse modo, o anúncio da morte de Deus se revela ainda mais ousado e radical, na medida em que não suprime, mas permite um novo cenário para se pensar o religioso. Esse novo arranjo se dá por meio da vontade de poder que reestrutura a realidade em torno de sua dinâmica de produção de sentido, suprimindo aquela sensação provocada pela morte de Deus, a saber, de que tudo é vão, sem sentido. Por conseguinte, essa religiosidade que nasce a partir da vontade de poder se distancia de esperanças ultraterrenas para assumir uma postura de afirmação dominante da vida.

Como o próprio Nietzsche atesta:

sim, não devemos inclusive rejeitar a perspectiva de que a vitória total e definitiva do ateísmo possa livrar a humanidade desse sentimento de estar em dívida com seu começo, sua causa prima [causa primeira]. $\mathrm{O}$ ateísmo e uma espécie de segunda inocência são indispensáveis (NIETZSCHE, 1978, §20, p. 79, grifos do autor).

Ora, o que realmente importa ressaltar nessa citação é que o ateísmo nietzschiano está para além do ateísmo teórico, tradicional. Ao registrar que Deus está morto, Nietzsche "limita-se a constatar a ausência do divino na cultura do seu tempo, acusando, pelo contrário, por essa ausência e morte o pensamento metafísico" (PENZO; GIBELLINI, 1998, p. 32). Em resumo, a mensagem da morte de Deus sinaliza o declínio do pensamento metafísico. 


\section{Considerações Finais}

O anúncio da morte de Deus adquire no âmbito da filosofia nietzschiana uma amplitude que se tornaria superficial restringi-lo a uma fórmula violentamente anticristã, como se o autor de $O$ Anticristo estivesse criando valores anticristãos. Compreender Nietzsche para além de um mero demolidor do cristianismo, porém, não tem a pretensão de deslocá-lo ingenuamente para a linhagem cristã, fazendo dele um cristão religioso. A morte de Deus revela que o problema religioso em Nietzsche trata-se, no fundo, de questões bem mais abrangentes, sobretudo para o campo investigativo filosófico, do que meramente promover o ateísmo ou a descrença. O sentido da morte de Deus foi entendido enquanto a experiência da decadência de tudo que se quis ou queira se portar como fundamento último, isto é, de qualquer estrutura absoluta da realidade.

Mas de onde surgiu a crença no fundamento? Buscou-se evidenciar que, para Nietzsche, as categorias filosóficas são meros hábitos gramaticais. Foi a crença na gramática que consolidou a crença na relação de causa e efeito. $\mathrm{O}$ velho hábito gramatical de atribuir um ator a toda ação possibilitou que se chegasse à ideia de sujeito, de vontade, de eu, de Deus. Portanto, com o nascimento da linguagem também se compreendeu o nascimento da noção de Deus-fundamento, pois foi justamente o entendimento de que na realidade subjaz certa estabilidade em meio à mudança que viabilizou a vida em sociedade.

\section{Referências}

ALVES, R. O enigma da religião. $4^{\text {a }}$ ed. Campinas: Papirus, 1988.

BIBLIA. Bíblia de Jerusalém. São Paulo: Paulus, 2004.

CABRAL, A. M. Niilismo e hierofania: uma abordagem a partir do confronto entre Nietzsche, Heidegger e a tradição cristã - Nietzsche, cristianismo e o Deus não-cristão. V. 1. Rio de Janeiro: Mauad X: Faperj, 2014.

CASANOVA, M. A. A religião da terra: o lugar do sagrado no pensamento de Friedrich Nietzsche. In: FEITOSA, C.; BARRENECHEA, M. A. de; PINHEIRO, P. (Orgs.). A fidelidade à terra: arte, natureza e política - Assim Falou Nietzsche IV. Rio de Janeiro: DP\&A, 2003. 
EAGLETON, T. A morte de Deus na cultura. Rio de Janeiro: Record, 2016.

HEIDEGGER, M. A constituição onto-teo-lógica da metafísica. In: Que é isto - A filosofia? Identidade e diferença. São Paulo: Livraria Duas Cidades, 1971.

MACHADO, R. Nietzsche e a verdade. São Paulo: Paz e Terra, 1999.

MOURA, C. A. R. de. Nietzsche: civilização e cultura. São Paulo: Martins Fontes, 2005.

NIETZSCHE, F. A gaia ciência. Trad.: Paulo César de Souza. São Paulo: Companhia das Letras, 2001.

Crepúsculo dos Ídolos, ou como se filosofa com o martelo. Trad.: Paulo César de Souza. São Paulo: Companhia das Letras, 2006.

- Sobre verdade e mentira no sentido extra-moral. Trad. Rubens Rodrigues Torres Filho. 2a ed. São Paulo: Abril Cultural, 1978.

. O Anticristo: maldição ao cristianismo: Ditirambos de Dionísio. Trad.: Paulo César de Souza. São Paulo: Companhia das Letras, 2007.

PENZO, G.; GIBELLINI, R. Deus na filosofia do século $X X$. São Paulo: Loyola, 1998.

PIRES, Frederico Pieper. A noção de metafísica segundo G. Vattimo. Mimeo. Juiz de Fora, 2016.

RICOEUR, P. Religião, Ateísmo, Fé. In: $O$ conflito das interpretações: ensaios de hermenêutica. Rio de Janeiro: Imago Editorial LTDA, 1978, p. 368-389.

VATTIMO, G. Depois da cristandade: por um cristianismo não religioso. Rio de Janeiro: Record, 2004.

. Diálogo com Nietzsche. São Paulo: WMF Martins Fontes, 2010.

YOUNG, J. Friderich Nietzsche: uma biografia filosófica. Rio de Janeiro: Forense, 2014. 